\title{
Kefektifan Bahan Ajar Ilmu Pengetahuan Alam Model Learning Cycle 7e Untuk Kelas V
}

\author{
Fembriani, S.Pd.,M.Pd ${ }^{1)}$, Nela Rofisian, S.Pd.,M.Pd ${ }^{2)}$ \\ ${ }^{1}$ Pendidikan Guru Sekolah Dasar, dan Universitas Widya Dharma \\ E-mail: fembrianiani@gmail.com \\ ${ }^{2}$ Pendidikan Guru Sekolah Dasar, dan Universitas Widya Dharma \\ E-mail: rofisian@yahoo.co.id
}

\begin{abstract}
Abstrak
Proses pembelajaran dalam KTSP memerlukan pengembangan bahan ajar. Observasi yang peneliti lakukan di kelas $\mathrm{V}$ pada lima sekolah dasar, $80 \%$ guru tidak membuat bahan ajar sendiri, 60\% SD masih menggunakan bahan ajar teacher center, dan $50 \%$ belum mengembangkan bahan ajar active learning. Penelitian ini menggunakan model pengembangan Plomp dengan tujuan untuk memperoleh bahan ajar yang efektif. Subjek uji coba adalah siswa kelas V SD Negeri Grujugan sebagai kelas eskperimen, dan SD Negeri Kritig sebagai kelas kontrol. Teknik analisis data yang digunakan adalah uji beda dua rata-rata dan uji $\mathrm{N}$-gain. Hasil Penelitian menunjukan implementasi bahan ajar terbukti efektif karena setelah diberi perlakuan menggunakan model learning cycle 7E terdapat perbedaan antara kelas kontrol dan ekperimen dengan nilai signifikansi 0,02<0,05 dan peningkatan hasil $\mathrm{N}$-gain kelas eksperimen sebesar 0,62 yang menunjukan kriteria sedang. Simpulan yang diperoleh dari penelitian ini adalah pengembangan bahan ajar IPA model learning cycle 7E adalah efektif.
\end{abstract}

Kata Kunci: Keefektifan, learning cycle 7E, Bahan Ajar IPA

\begin{abstract}
The learning process in school based curiculum requires the development of instruction source of natural science. observation on V class that researchers do at five schools, $80 \%$ of teachers do not make their own learning device, $60 \%$ of elementary school teacher still use the learning center, and 50\% have not yet developed learning tools to active learning. This study uses a model of development Plomp in order to obtain a, effective learning device. Subject trial is Elementary School fifth grade students as a class Grujugan experimentation, and the Elementary School Kritig as the control class. The analysis techniques are two different test average and $\mathrm{N}$-gain test. The result of research showed implementation of valid learning tool proven effective because after being treated using the model $7 \mathrm{E}$ learning cycle there is a difference between the control and experimental classes with significant value of $0.02<0.05$ and increased yield of $\mathrm{N}$-gain experimental class of 0.62 which indicates the medium criteria. The conclusions of this reserch is Developing Instruction Source Of Natural Science with learning cycle 7E is effective.
\end{abstract}

Keyword: Effectiveness, Learning Cycle 7E, Instruction Source Of Natural Science

\section{PENDAHULUAN}


Proses pembelajaran dalam KTSP memerlukan pengembangan bahan ajar. Bahan ajar adalah sekumpulan sarana yang harus dipersiapkan dan digunakan oleh guru dalam proses pembelajaran di kelas. Semakin baik penyusunan perangkat pembelajaran yang dikembangkan, semakin baik pula proses pembelajarannya. Bahan ajar disusun secara sistematis. Bahan ajar yang sistematis dapat memunculkan ide ide kreatif siswa. Hal ini dilakukan agar siswa mencapai kompetensi yang diharapkan.

Pengembangan bahan ajar yang sistematis diharapkan mampu meningkatkan kemampuan berpikir kritis siswa sekolah dasar. Kemampuan berpikir kritis merupakan kemampuan berpikir kompleks. Hal ini didukung pendapat Snyder \& Snyder (2008) bahwa critical thinking (proses intelektual disiplin aktif dan terampil konseptualisasi, menerapkan, menganalisis, mensintesis, dan/atau mengevaluasi informasi yang dikumpulkan dari, atau dihasilkan oleh, observasi, pengalaman, refleksi, penalaran, atau komunikasi, sebagai panduan untuk keyakinan dan tindakan. Melalui kemampuan berpikir kritis, siswa lebih mudah memahami konsep dan peka terhadap masalah. Pembelajaran IPA perlu mengembangkan berpikir kritis agar siswa memiliki kemampuan bersikap dan berperilaku adaptif dalam menghadapi tantangan. Dengan kemampuan berpikir kritis, siswa diharapkan mampu menganalisis permasalahan dalam kehidupan sehari-hari.

Pembelajaran selama ini belum mengembangkan kemampuan berpikir kritis. Che (2002) mengatakan bahwa guru merasa tidak mudah bagi mereka untuk melepaskan diri dari kebiasaan lama yaitu mengajar berpusat pada guru. Mereka mengakui bahwa mereka tidak menerima pendidikan guru yang memadai untuk mengajar berpikir kritis. Schneider (2002) menjelaskan tugas kita dalam pendidikan membekali siswa sekolah dasar dengan ketrampilan dan strategi berpikir kritis untuk memecahkan masalah. Tantangannya adalah mengubah tujuan instruksional sesuai dengan kehidupan nyata dan kegiatan pembelajaran sesuai dengan tahapan perkembangan siswa.

Observasi yang peneliti lakukan dengan guru kelas V di lima sekolah, sebagai berikut: 1 guru menyusun bahan ajar sendiri, 1 guru membuat secara 
kelompok yaitu KKG, dan 3 lainnya download. Dari data tersebut 80\% guru tidak membuat bahan ajar sendiri. Dapat disimpulkan bahan ajar masih bersifat formalitas dan hanya memenuhi kewajiban administrasi.

Bahan ajar IPA kelas V di lima SD belum dikembangkan dengan model pembelajaran yang student center (berpusat pada siswa). Observasi yang peneliti lakukan diperoleh pembelajaran masih ceramah (teacher center), 2 lainnya menggunakan kerja kelompok dan melakukan percobaan. Didapatkan hasil $60 \%$ SD masih menggunakan pembelajaran teacher center.

Dari hasil observasi, Pembelajaran di SD Negeri Grujugan sebagai berikut: bahan ajar tidak dibuat sendiri hanya untuk memenuhi formalitas, model pembelajarannya masih teacher center, serta belum mampu meningkatkan berfikir kritis.

Berdasarkan fakta tersebut, diupayakan suatu rancangan pembelajaran dengan model tertentu yang mampu meningkatkan kemampuan berpikir kritis siswa. Untuk mengatasi permasalahan-permasalahan di atas, penelitian ini mengembangkan perangkat pembelajaran model learning cycle 7E. Bahan ajar ini diharapkan mampu meningkatkan berpikir kritis siswa. Bahan ajar dengan model learning cycle 7E ini untuk menciptakan kondisi belajar yang kondusif, aktif, dan menarik. Dengan pembelajaran learning cycle 7E maka hasil belajar akan meningkat.

Hal ini terbukti dari penelitian yang dilakukan Qarareh (2012) penelitian ini merekomendasikan penggunaan learning cycle 7E dalam mengajar konsep-konsep ilmiah dan merancang software instruksional. Hasil penelitian tersebut menunjukan bahwa siswa yang dikenai perlakuan memiliki hasil belajar yang lebih baik secara signifikan, dibandingkan dengan siswa yang diberikan pembelajaran konvensional. Penelitian lain yang mendukung yaitu yang dilakukan Cardak, et al (2008) menyatakan model pembelajaran learning cycle 7E lebih efektif digunakan dalam meningkatkan keberhasilan siswa sekolah dasar kelas 6 pada topik sistem peredaran darah dibandingkan dengan kelas kontrol.

Pembelajaran model learning cycle 7E diharapkan membantu siswa agar mampu mengembangkan pengetahuan yang dimilikinya. Pembelajaran ini 
bersumber dari teori Konstruktivis yaitu pendidikan untuk membangkitkan pemikiran peserta didik dan membuatnya aktif, interaktif dan positif selama proses belajar. Qarareh (2012) menjelaskan learning cycle 7E adalah proses kognitif yang aktif, yang siswa lewati berbagai pengalaman pendidikan eksploratif yang memungkinkan dia untuk mengeksplorasi pengetahuan dimaksudkan untuk pemikiran manusia. Belajar menggunakan learning cycle 7E sebagai pembelajaran bermakna yang meningkatkan prestasi siswa. Tahapan pembelajaran learning cycle 7E yaitu (a) memunculkan pengetahuan awal siswa (elicit), (b) melibatkan (engagement), (c) menyelidiki (exploration), (d) penjelasan (explanation), (e) menguraikan (elaboration), (f) menilai (evaluation), dan (g) memperluas (extend). Dengan tahapan di atas, pembelajaran learning cycle 7E ini akan menumbuhkan cara berpikir kritis siswa karena pembelajaran ini berpusat pada siswa. Jadi learning cycle 7E merupakan rangkaian tahap-tahap kegiatan (fase) yang diorganisasi sedemikian rupa sehingga pebelajar dapat menguasai kompetensi-kompetensi yang harus dicapai dengan lima langkah elicit, engagement, exploration, explanation, elaboration, evaluation, dan extend.

\section{METODE PENELITIAN}

Pengmbangan bahan ajar IPA dengan model learning cycle 7E materi struktur bumi dan benda langit mengacu pada model pengembangan dari Plomp (Plomp \& Nieveen, 2007) sebuah model yang terbagi menjadi lima fase yaitu: 1) fase investigasi awal, 2) fase desain, 3) fase realisasi atau konstruksi, 4) fase tes, evaluasi, dan revisi, dan 5) fase implementasi. Subjek uji coba penelitian ini terbagi menjadi 2 bagian yaitu: (1) Subjek uji coba skala kecil adalah siswa kelas V SD Negeri Grujugan Kabupaten Kebumen, (2) subjek uji coba pemakaian bahan ajar eksperimen adalah siswa kelas V SD Negeri Grujugan Kabupaten Kebumen.

Jenis data yang dikumpulkan berupa data kualitatif dan kuantitatif, yang mencakup data hasil belajar siswa berupa pretest dan posttest, hasil analsis perbedaan hasil belajar kelas kontrol dan eksperimen. Dalam teknik penelitian ini teknik pengumpulan data yang dilakukan dengan cara sebagai berikut: (1) observasi dilakukan untuk mengumpulkan data kondisi awal, (2) teknik dokumentasi 
digunakan untuk memperoleh data yang telah ada berupa data nilai IPA siswa, daftar nama siswa, (3) teknik tes digunakan untuk mengukur skor tingkat penguasaan konsep siswa dari materi yang diajarkan.

\section{HASIL PENELITIAN DAN PEMBAHASAN}

\section{a. Analisis Keefektifan}

Keefektifan bahan ajar yang dikembangkan dilakukan dengan uji t untuk mengetahui ada perbedaan kelas kontrol dan kelas ekperimen serta uji $\mathrm{N}$-gain untuk mengetahui peningkatan pretest-posttest kelas eksperimen.

Perolehan hasil uji normalitas data nilai pretest kelas kontrol dan eksperimen adalah signifikan hasil belajar 0,28>0,05 menunjukan bahwa data berdistribusi normal atau jika digambarkan dalam kurva normal data berada pada daerah penolakan Ho. Perolehan hasil uji normalitas data nilai pretest kelas kontrol dan eksperimen adalah signifikan hasil belajar 0,28 > 0,05 menunjukan bahwa data berdistribusi normal.

Pada uji homogenitas data nilai preetest kelompok eksperimen dan kontrol diperoleh nilai signifikan 0,12>0,05 maka Ho diterima atau kedua kelompok mempunyai varian yang sama (varian datanya homogen). Uji homogenitas data nilai preetest kelompok eksperimen dan kontrol diperoleh nilai signifikan 0,25> 0,05 maka Ho diterima atau kedua kelompok mempunyai varian yang sama (varian datanya homogen).

Nilai uji-t pretest menunjukan bahwa nilai siginfikansi 0,57>0,05 maka Ho diterima, artinya hipotesis yang menyatakan tidak ada perbedaan antara kelompok eksperimen dan kelompok kontrol diterima. Jadi disimpulkan bahwa sebelum diberikan perlakukan kedua kelompok memiliki kemampuan awal yang sama. Nilai uji $t$ posttest menunjukan signifikansi 0,002 < 0,05 maka Ho ditolak dan Ha diterima, artinya hipotesis yang menyatakan tidak ada perbedaan antara kelompok eksperimen dan kelompok kontrol ditolak, yang berarti bahwa setelah diberi pembelajaran dengan bahan ajar learning cycle 7E, ternyata perolehan nilai posttest (nilai hasil belajar) kelompok eksperimen lebih tinggi dari kelompok kontrol. Jadi disimpulkan bahwa ada perbedaan rata-rata nilai posttest antara kelompok 
eksperimen dengan kelompok kontrol. Dalam hal ini nilai rata-rata posttest kelompok eksperimen lebih baik daripada kelompok kontrol.

Untuk mengetahui kefktifan bahan ajar yang dikembangkan dapat dilihat dari perbandingan peningkatan hasil belajar tiap individu secara keseluruhan melalui perbandingan rata-rata peningkatan nilai pretest dan posttes antara kelas eksperimen dan kelas kontrol menggunakan uji $\mathrm{N}$-gain pada tabel 1

Tabel 1.Perbandingan Rata-rata N-gain

\begin{tabular}{cccccc}
\hline \multicolumn{2}{c}{$\begin{array}{c}\text { Kelompok } \\
\text { Eksperimen }\end{array}$} & \multicolumn{5}{c}{ Kelompok Kontrol } \\
\hline Pretest & Posttest & N-gain & Pretest & Posttest & N-gain \\
\hline 157,7 & 211 & 0,62 & 141,4 & 179,2 & 0,35 \\
\hline
\end{tabular}

Kriteria keefektifan

$\begin{array}{ll}\text { Tinggi } & : \mathrm{g}>0,70 \\ \text { Sedang } & : 0,70>\mathrm{g}>0,30 \\ \text { Rendah } & : \mathrm{g}<0,30\end{array}$

Berdasarkan Tabel 1 dapat dilihat bahwa N-gain kelompok eksperimen 0,62 berada pada rentang 0,70>g $>0,30$ menunjukan kriteria sedang dan kelompok kontrol hanya 0,35. Dengan demikian dapat disimpulkan bahwa penggunaan bahan ajar model learning cycle 7E secara keseluruhan efektif untuk meningkatkan hasil belajar siswa pada materi alat pencernaan makanan dan kesehatan.

\section{b. Pembahasan Hasil Pengembangan bahan ajar yang Efektif.}

Keefektifan bahan ajar learning cycle 7E diukur dari (1) ada perbedaan kelas ekperimen dan kelas kontrol, (2) ada peningkatan hasil belajar kelas eksperimen.

Nilai uji-t pretest menunjukan bahwa nilai siginfikansi 0,567 >0,05 maka Ho diterima, artinya hipotesis yang menyatakan tidak ada perbedaan antara kelompok eksperimen dan kelompok kontrol diterima. Jadi disimpulkan bahwa sebelum diberikan perlakukan kedua kelompok memiliki kemampuan awal yang sama rata-rata. 
Setelah perlakuan, perolehan nilai posttest kedua kelompok menunjukan hasil yang berbeda. Perbedaan yang signifikan nilai uji-t menunjukan nilai signifikansi 0,002 < 0,05 maka Ho tolak, artinya hipotesis yang ada perbedaan antara kelompok eksperimen dan kelompok kontrol ditolak. Jadi disimpulkan bahwa Ha terima, yang artinya ada perbedaan kelas ekperimen dan kelas kontrol setelah diberi perlakukan.

Nilai rata-rata perolehan skor posttest kelas eksperimen 200,2 dengan nilai rata-rata 84,3 sedangkan rata-rata perolehan skor posttest kelompok kontrol 175,2 dengan nilai rata-rata 73. Dari perhitungan kasar selisih rata-rata perolehan nilai posttest tersebut sudah diprediksi bahwa peningkatan penguasaan konsep kelas eksperimen lebih tinggi dibandingkan kelas kontrol, yang artinya ada perbedaan rata-rata perolehan nilai postest antara kelas eksperimen dengan kelas kontrol. Keefektifan bahan ajar ditunjukan dengan kenaikan rata-rata nilai posttest kelas eksperimen yang lebih baik daripada kelompk kontrol.

\section{SIMPULAN}

Peengembangan bahan ajar telah dilakukan, diperoleh data tingkat keefektifan bahan ajar IPA dengan model learning cycle 7E SD N Grujugan berada pada kriteria sedang, dengan perolehan nilai peningkatan pencapaian ( $\mathrm{N}-$ gain) sebesar $0,62 \%$. Perbedaan nilai rata-rata pretest antara kelas eksperimen dan kelas kontrol menunjukan nilai rata-rata kelas eksperimen 151,4 lebih baik daripada kelas kontrol 141,4, serta peningkatan nilai rata-rata posttest kelas eksperimen 204,4 juga lebih baik daripada peningkatan nilai rata-rata kelompok kontrol 179,2. Perolehan nilai posttest kedua kelompok menunjukan hasil yang berbeda. Perbedaan yang signifikan nilai uji-t menunjukan nilai signifikansi 0,002 <0,05 maka Ho tolak, artinya hipotesis yang ada perbedaan antara kelompok eksperimen dan kelompok kontrol ditolak. Jadi disimpulkan bahwa Ha terima, yang artinya ada perbedaan kelas ekperimen dan kelas kontrol setelah diberi perlakukan.

\section{DAFTAR PUSTAKA}

Arikunto, S. 2012. Dasar-Dasar Evaluasi Pendidikan. Jakarta: Bumi Aksara. 
Brookfield, S. D. 2012. Teaching For Critical Thinking. Amerika: Jossey-Bass.

Cardak O, Dikmenli M, \& Saritas O. 2013. Effect Of 5e Instructional Model In Student Success In Primary School 6 Th Year Circulatory System Topic. Journal Asia Pasific Forum on Science Learning and Teaching, 9(13).

Che, S. F. 2002. Teaching Critical Thinking Skills in a Hong Kong Secondary School. Journal Asia Pasific Education Review. 3(1).

Ergin I, Kanli U, Yasin U. 2008. An Example for Effect of 5E Model on the Academic Success and Attitude Levels of Student:"Inclined Projectile Motion”. Journal of Turkish Science Education.5 (3).

Hamdani, M.A. 2010. Strategi Belajar Mengajar. Bandung: Pustaka setia.

Hanuscin, D. L. \& Lee, M.H. 2008. Using the Learning Cycle as a Model for Teaching the Learning cycle to Preservice Elementary Teachers. Journal of Elementary Science Education, 20 (2).

Indriyani, I.R. 2013. Pengembangan LKS Fisika Berbasis Siklus Belajar (Learning Cycle) 7E untuk meningkatkan Hasil Belajar dan Meningkatkan Kemampuan Berpikir Kritis pada Siswa SMA Kelas X Pokok Bahasan Elektromagnetik. FIP Pascasarjana Universitas Ahmad Dahlan. Yogyakarta.

Jufri, A W. 2013. Belajar dan Pembelajaran SAINS. Bandung: Pustaka Reka Cipta.

Marek, E.A. 2008. Why the Learning cycle. Journal of Elementary Science Education, 20 (3).

Marek E.A, Maier S.J, \& Micam F. 2008. Assesing Understanding of the Learning Cycle: The ULC. Journal Science Teacher Education, 19 (375-389).

Meltzer, D.E. 2002. The Relationship between mathemathic preparation and conceptual learning gain in physics: a possible "hidden variabel" in diagnostic pretest scores. American Journal Physics. Vol. 12. No. 70.

Ngalimun. 2014. Strategi dan Model Pembelajaran. Yogyakarta: Aswaja Presindo.

Qarareh, A.O. 2012. The Effect of Using the Learning Cycle Method in Teaching Science on the Educational Achievement of the Sixth Graders. International Journal of Science Education. 4 (123-132).

Putra, S.R. 2013. Desain Belajar Mengajar Kreatif Berbasis Sains. Jakarta Diva Press. 
Plomp, T \& Nieveen, N. 2007. An Introduction to Educational Design Research. Netherland: Netzodruk,enschede.

Rusman. 2012. Model-model Pembelajaran. Jakarta: Raja Grapindo Perada.

Sani, R.A. 2013. Inovasi Pembelajaran. Jakarta: Bumi Aksara.

Sanjaya, W. 2006. Strategi Pembelajaran Berorientasi Standar Proses Pendidikan. Jakarta : Kencana.

Snyder, M. J \& Snyder, L. G. 2008. Teaching Critical Thinking and Problem solving Skill. The Delta Pi Epsilon Journal. 1 (2).

Schneider, V. 2002. Critical Thinking in the Elementary Classroom: Problem and Solutions. Educator Publising Service. EPS book.

Sudijono, A. 2006. Pengantar Evaluasi Pendidikan. Jakarta: Raja Grafindo Persada.

Sugiantara, Pt., Kusmariyatni, Nym., \& Marguyasa. 2013. Pengaruh Model Pembelajaran Learning Cycle 5E Terhadap Hasil Belajar Siswa Kelas V di gugus VII Kecamatan Buleleng. PGSD FIP. Universitas Pendidikan Ganesha Singaraja Indonesia.

Sugiyono. 2010. Statistika untuk Penelitian. Bandung: Alfabeta.

Trianto. 2009. Mendesain Model Pembelajaran Inovatif-Progresif. Jakarta: Prestasi Pustaka.

Waswa, P \& Felicia, O. 2013.Enhancing Student' Achievement in Chemistry through the Piagentian Model The Learning Cycle. Journal for CrossDiscipilinary Subject in Education (IJCDSE), 4 (4).

Wena, M. 2014. Strategi Pembelajaran Inovatif kontemporer Suatu Tinjauan Konseptual Operasional. Jakarta: Bumi Aksara. 